\title{
Erratum to: Short-Term Exposure to Enriched Environment in Adult Rats Restores MK-801-Induced Cognitive Deficits and GABAergic Interneuron Immunoreactivity Loss
}

\author{
Ane Murueta-Goyena ${ }^{1} \cdot$ Naiara Ortuzar $^{1}$ - Pascual Ángel Gargiulo ${ }^{2}$. \\ José Vicente Lafuente ${ }^{1,3,4} \cdot$ Harkaitz Bengoetxea $^{1}$
}

Published online: 30 September 2017

(C) Springer Science+Business Media, LLC 2017

Erratum to: Mol Neurobiol.

https://doi.org/10.1007/s12035-017-0715-Z

The original version of this article unfortunately contained a mistake. The name of the author was changed from "Pascual Gargiulo" to "Pascual Ángel Gargiulo." The authors missed to include the second name "Ángel" in the final manuscript. The original article was corrected.

The online version of the original article can be found at https://oi.org/ 10.1007/s12035-017-0715-z

Ane Murueta-Goyena

ane.muruetagoyena@ehu.eus

1 LaNCE, Department of Neuroscience, University of the Basque Country (UPV/EHU), Barrio Sarriena, 48940 Leioa, Bizkaia, Spain

2 Laboratory of Neurosciences and Experimental Psychology, Area of Pharmacology, Department of Pathology, Faculty of Medical Sciences, National Council of Scientific and Technical Research, National University of Cuyo, Mendoza, Argentina

3 Nanoneurosurgery Group, BioCruces Health Research Institute, 48903 Barakaldo, Bizkaia, Spain

4 Faculty of Health Science, Universidad Autónoma de Chile, Santiago de Chile, Chile 